\title{
Helmintoses Intestinais: 0 Processo de Comunicação e Informação no Programa de Educação e Saúde em Verminose ${ }^{1}$
}

\author{
Intestinal Helminthiasis: The Process of Communication and Information \\ in a Health Education Program on Intestinal Worms
}

\author{
Dalva A. Mello ${ }^{2}$ \\ Elisete S. Pedrazzani ${ }^{3}$ \\ Clemência P. Pizzigatti ${ }^{3}$
}

MELLO, D. A.; PEDRAZZANI, E. S. \& PIZZIGATTI, C. P. Intestinal Helminthiasis: The Process of Communication and Information in a Health Education Program on Intestinal Worms. Cad. Saude Públ, Rio de Janeiro, 8 (1): 77-82, jan/mar, 1992.

This paper provides a framework for analysis of the effectiveness of the communication process used in the Health Promotion Program implemmented in two schools in the town of Santa Eudóxia (state of São Paulo), as well as in one of the Education and Health workshops. The materials were produced in cooperation with the local community and include folders, manuals, murals, panels and illustrative drawings. One of the most significant aspects of the communication process was the identification of the mother as the principal health promoter in the family. The results showed that the techniques and methods were appropriate to the needs of the people and may be used as a pedagogic instrument in developing health programs.

Keywords: Helminthiasis; Helminthiasis Prevention; Health Education; Communication in Health

\section{INTRODUÇÃO}

Os meios de comunicação são instrumentos importantes em programas de intervenção em saúde.

No Brasil, tanto nas Secretarias de Saúde estaduais ou municipais quanto no Ministério da Saúde, existem setores especializados na área de Comunicação Social que se dedicam, entre outras tarefas, à produção de material ilustrativo voltado para programas de controle, profilaxia, vacinação etc.

\footnotetext{
${ }^{1}$ Trabalho apoiado em parte pelo CNPq (Proc. $n^{\text {s }}$ 406472/84) e Fesima, Secretaria de Saúde do Estado de São Paulo.

${ }^{2}$ Departamento de Patologia da Faculdade de Ciências da Saúde, Universidade de Brasilia, Asa Norte, Brasilia, DF, 70910, Brasil.

${ }^{3}$ Centro de Ciências Biologicas e da Saude da Universidade Federal de Sāo Carlos, Caixa Pastal 676, São Carlos, SP, 13560, Brasil.
}

Por outro lado, em ações educativas conduzidas nesses tipos de programas, a utilização de instrumentos de comunicação constitui-se em canal importante e facilitador da participação, como também contribui para proporcionar aprendizagem de conteúdo informativo.

Nas pesquisas conduzidas no projeto sobre Helmintoses Intestinais, no subdistrito de Santa Eudóxia (São Carlos, São Paulo), por Mello et al. (1988) e Pedrazzani et al. (1988, 1989), foram utilizadas várias formas e instrumentos de comunicação que tiveram por finalidade garantir a compreensão do programa de intervenção. Este trabalho tem por objetivo analisar a estratégia ilustrativa dessas formas e instrumentos de comunicaçāo. O material foi produzido durante o desenvolvimento do projeto, na campanha de intervenção, nos cursos de Educação e Saúde, nos módulos educativos em ciências aplicadas, nas duas escolas de Santa Eudóxia e na Feira de Educação e Saúde em Verminose. 


\section{MATERIAIS}

As fontes que geraram a produção dos materiais para comunicação foram os vermes (em conservação, lâminas, desenhos acadêmicos, diapositivos, livro texto); o corpo humano (desenho da anatomia e fisiologia, conceitos de saneamento e higiene); os resultados obtidos numa sequiência de eventos ocorridos durante o projeto, como a aplicação do questionário sobre conhecimentos, atitudes e percepção da população; e os resultados dos exames clínicos e laboratoriais de sangue e fezes (Mello et al., 1988 e Pedrazzani et al., 1988, 1989).

A organização e a elaboração desses materiais para a comunicação compreenderam ilustraçōes, mensagens e conteúdo informativo teórico. Os recursos utilizados para tal fim foram os seguintes:

1. Cartazes - focalizando o anúncio do projeto como acontecimento comunitário, enfocando a importância do problema e passando informações - ordens, convites, mensagens.

2. Panfletos e Comunicados - recados ilustrados ou não que eram levados para casa e constituíam um meio de intercâmbio dos fatos acontecidos ou a acontecer.

3. Painéis e Murais - colocados nas escolas e Posto de Saúde.

4. Manuais - dois tipos de manuais foram utilizados: o da equipe animadora, que tinha por objetivo orientar os cursos e aqueles produzidos pelos responsáveis dos escolares como resultado dos cursos aplicados sobre o tema Verminose.

5. Desenhos - em cartazes e nos manuais produzidos pelas crianças e responsáveis.

\section{PROCEDIMENTOS E RESULTADOS}

O modelo de informação publicitária utilizada para convocar a comunidade foi representado por uma linguagem gráfica e falada, baseada nos resultados obtidos da pesquisa em que foi aplicado o questionário já mencionado, sobre os conhecimentos, atitudes e percepções da população. Os resultados dessas pesquisas resgataram o estágio de valores e a capacidade da linguagem falada e perceptiva. Com esses dados, foi possível verificar, também, a importância que a manifestação gráfica, através do desenho, representava para a compreensão da população. É importante, ainda, destacar que, neste mesmo questionário, a mãe foi identificada como a figura principal, sendo o elo de ligação mais importante na família no que se refere aos cuidados imediatos dos problemas de saúde. Dessa forma, considerou-se a Mulher a personagem chave de todo o projeto, surgindo, assim, a Mulher-Símbolo da campanha, presente em todas as capas dos manuais e nos cartazes ao lado da chamada, Guerra às Lombrigas - Menos Doença, Melhor.

Os cartazes, panfletos e painéis tinham sempre frases curtas e concretas, cujo objetivo era que a comunicação alcançasse toda a população envolvida, articulada à noção do valor e da importância do tema. Seguem-se alguns exemplos:

A verminose, em qualquer idade, atrapalha a saúde.

Devemos ter o maior cuidado para nāo pegar vermes, e isso depende de nós.

As crianças crescem sem saúde.

O manual de orientação em helmintoses intestinais, elaborado pela equipe animadora do processo, foi o veículo de instrução simplificada ao alcance dos profissionais de saúde de nível médio e dos professores das escolas da vila Santa Eudóxia. O conteúdo abordou o mínimo necessário, com ilustrações didáticas e esclarecedoras. Esses manuais tinham por objetivo facilitar a orientação e coordenação dos cursos aplicados aos responsáveis dos escolares.

Os cursos aplicados a esses responsáveis tiveram por produto e fonte de avaliação a elaboração de três manuais. Verificou-se, durante a elaboração desses manuais, que o prazer de escrever e desenhar foi maior do que os impedimentos de alfabetização e o saber desenhar. $O$ trabalho ganhava prioridade $e$ amplo alcance educativo, na medida em que as discussōes ocorriam de forma espontânea, respeitando-se os valores identificados pelo grupo.

As informações básicas sobre o saneamento local e os vermes desenhados constituíram-se 


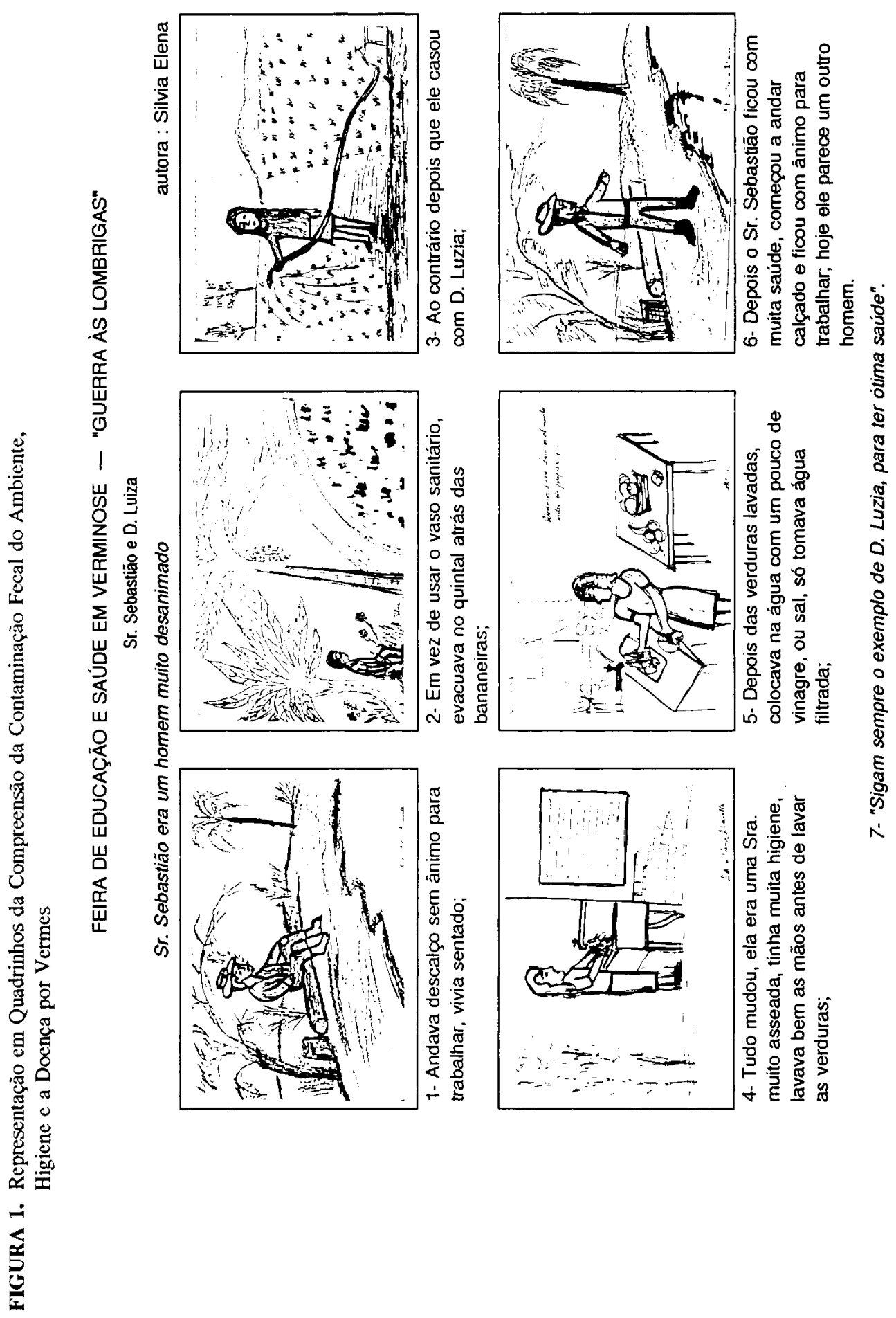


em estímulos para o reconhecimento do problema da doença e para o sentimento de aversão à possibilidade de contaminação. Assim a sujeira passou a ter significado de perigo de doença.

Para ressaltar contaminação ambiental pelas fezes, higiene e a doença por vermes, destacou-se, entre os trabalhos produzidos, uma estória em quadrinhos, elaborada por um dos participantes (Figura 1).

A análise da linguagem infantil e da expressão criativa, utilizada no desempenho do conteúdo escolar em Educação e Saúde: Verminose, foi feita a partir do produto resultante do trabalho pedagógico desenvolvido entre professores e alunos ao longo do ano didático (Pedrazzani et al., 1989).

Nos trabalhos de comunicação realizados pelos professores, como material pedagógico, e pelos alunos, como resultado de seu aprendizado, percebeu-se que, em sua maioria, eram estereotipados e ligados diretamente ou às ilustrações de livros escolares ou de riscos de bordados domésticos. Esse aspecto tornou-se mais evidente nas classes da $5^{\mathrm{a}}$ à $8^{\mathrm{a}}$ série. Grande parte dos trabalhos produzidos refletiu cópia direta das referidas ilustrações (Figura 2, a e b). Raros foram os desenhos criativos espontâneos e originais (Figura 3), sendo que alguns expressaram o visual do meio, tendo como objeto central a tradução do ambiente vivido e voltado para a preservação e conservação.

FIGURA 2. As Figuras A e B são exemplos de Trabalhos Realizados pelos Alunos, Copiados de Ilustrações de Livros Escolares

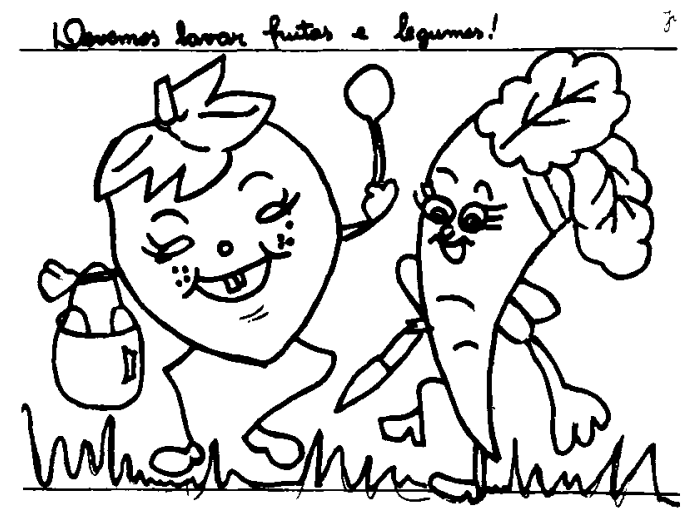

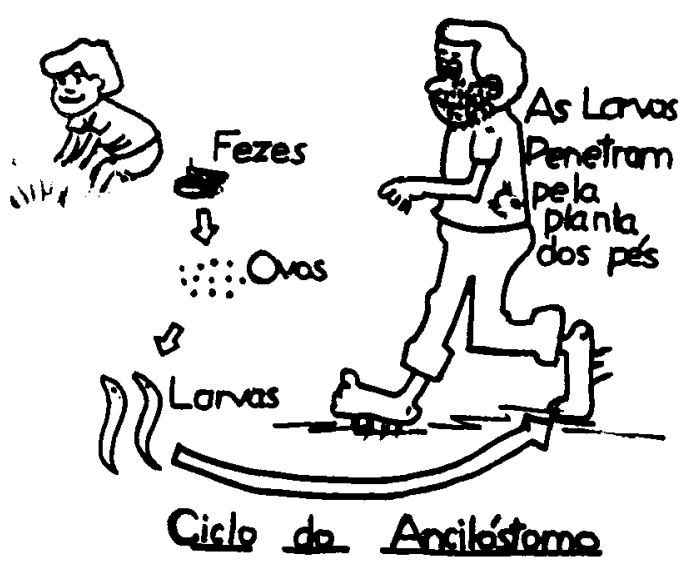

FIGURA 3. Ilustração Criativa que expressa o Visual da Contaminação do Meio Ambiente Vivido

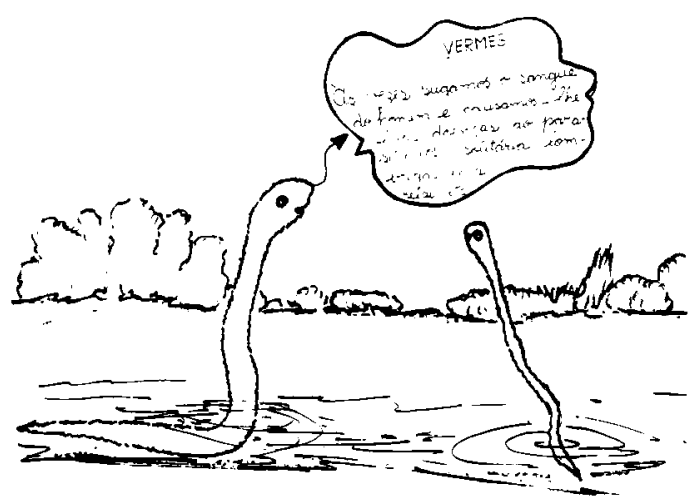

Esse problema está relacionado, em parte, com o despreparo do professor na área de ArteEducação, agravado pelas carências em relação à qualidade de material didático para o ensino, à disponibilidade de tempo, à liberdade de ação na programação do conteúdo pedagógico.

Schall et al. (1987), ao avaliarem o material pedagógico para ensino e profilaxia da esquistossomose, produzido por alunos de primeiro grau, observaram também resultados semelhantes aos das escolas de Santa Eudóxia quanto ao produto obtido, destacando como agravante $o$ fato de serem os programas de ensino feitos pelos próprios professores, que apenas copiam os indices dos livros adotados, colocando em cheque a eficiência do ensino através de esquemas e modelos recebidos prontos. 
A realização da Feira de Educação e Saúde em Verminose, que representou a síntese do projeto de intervenção, foi o ponto clímax de todo o processo de comunicação com e entre a população de Santa Eudóxia. Nesta etapa, a figura-símbolo da Mulher, expressa no convite e no painel de entrada para a Feira, foi retomada, sendo traduzida na mãe varrendo os vermes.

Os trabalhos realizados em equipe, geralmente as maquetes e cartazes maiores, foram destacados do restante. Todo esse conjunto de materiais, expostos ou veiculados durante a feira, constituiu-se em fonte dos elementos que conduziram, no evento, o processo de comunicação, fundamental para efetivar a participação do público em geral e as pessoas que, de forma direta ou indireta, atuaram no projeto.

\section{CONCLUSÕES}

$\mathrm{Na}$ proposta sobre a intervenção em verminose, no subdistrito de Santa Eudóxia (São Carlos, São Paulo), houve um processo de comunicação com o objetivo de ilustrar, demonstrar e consolidar as informações junto à comunidade. Como foi descrito, essa comunicação desenvolveu-se através de todo um conjunto de informações traduzido em panfletos, painéis, murais, manuais e programação curricular em saúde nas escolas municipal e estadual. Este conjunto foi elaborado na sequiência dos eventos que ocorreram durante $o$ desenvolvimento do projeto de intervenção.

Não obstante alguns acontecimentos que tiveram interferência no andamento dos trabalhos (greve, problemas institucionais ligados à programação formal do conteúdo escolar etc.), verificou-se que o significado de Saúde relacionado a Verminose, como objetivo do projeto e veiculado através das fontes de informação descritas acima, foi compreendido de forma eficiente e satisfatória.

Esse aspecto foi comprovado através de depoimentos de várias pessoas, da mobilização e participação da comunidade, como demonstrado por Pedrazzani et al. (1989) ao analisarem o programa de Educação e Saúde implementado durante o projeto.
A produção do material pedagógico de comunicação foi de entendimento da comunidade. Essa produção, somada às ilustrações ofertadas pela equipe, harmonizou-se em um programa onde o desenho, como símbolo de mensagem, foi permanente. Os desenhos realistas e concretistas dos manuais apresentaram-se como fonte de informação para os participantes e foram vivenciados durante experiências educacionais sobre o tema abordado.

O conteúdo estético visual, interpretando valores da comunidade, foi identificado nas histórias ou nas representações gráficas cenário e personagem - como objetos familiares da comunidade. Os desenhos foram respostas do percebido e vivenciado na natureza e no ambiente do educando. Por exemplo, os croquis do corpo humano, apresentados nos manuais tanto os aspectos da figura externa como do interior, foram uma identificação espelhada de cada um e, por isso mesmo, permitiram uma maior assimilação.

A comunicação através do desenho como linguagem foi um meio rápido e de largo alcance, conforme depoimento obtido nas reuniões conjuntas da equipe e participantes do projeto. $O$ desenho foi, também, um reforço de conteúdo, pois as imagens que simbolizavam completaram o pensamento e as mensagens ganharam efeitos de impacto. As imagens reprodutoras das cenas, atos ou fatos objetivaram e treinaram o conhecimento.

A Feira de Educação e Saúde em Verminose, que teve uma freqüência significativa da população (Pedrazzani et al., 1989), representou, também, a síntese do processo de comunicação, constituindo-se em motivação participativa fortemente vivenciada pelos escolares, seus responsáveis, professores e, de uma maneira geral, pela comunidade de Santa Eudóxia. Assim, a comunicação, veiculando a informação, esteve diretamente associada à participação e não apenas conduzindo disseminação de conteúdo, destacando-se a importância de se trabalhar com materiais e métodos facilitadores, que permitam a intervenção em níveis diferenciados, estreitando a participação ativa da população e dos profissionais nos programas de saúde. 


\section{RESUMO}

MELLO, D. A.; PEDRAZZANI, E. S. \& PIZZIGATTI, C. P. Helmintoses Intestinais: O Processo de Comunicação e Informação no Programa de Educação e Saúde em Verminose. Cad. Saúde Públ., Rio de Janeiro, 8 (1): 77-82, jan/abr, 1992.

No trabalho sobre intervenção em helmintoses intestinais, no subdistrito de Santa Eudóxia (São Carlos, São Paulo), foi conduzido um processo de comunicação com o objetivo de ilustrar, demonstrar e consolidar a informação sobre o programa junto à comunidade. A comunicação desenvolveu-se ao longo da seqüência de eventos que ocorreram durante o desenvolvimento do trabalho de intervenção, veiculando e disseminando informação associada à participação da comunidade.

Palaviras Chave: Helmintoses; Prevenção de Helmintoses; Educação em Saúde;

Comunicação em Saúde

\section{REFERÊNCIAS BIBLIOGRÁFICAS}

MELLO, D. A.; PRIPAS, S.; SANTORO, M. C.; FUCCI, M. \& PEDRAZZANI, E. S., 1988. Helmintoses Intestinais. I. Conhecimentos, atitudes e percepção da população. Revista de Saúde Pública, 22: 140-149.

PEDRAZZANI, E. S.; MELLO, D. A.; SANTORO, M. C.; PRIPAS, S.; FUCCI, M. \& BARBOSA, C. A. de A., 1988. Helmintoses Intestinais. II. Prevalência e correlação com renda, tamanho da familia, anemia e estado nutricional, Revista de Saúde Priblica, 22: 384.

PEDRAZZANI, E. S.; MELLO, D. A.; PRIPAS, S.; SANTORO, M. C; PIZZIGGATTI, C. \& FUCCI, M., 1989. Helmintoses Intestinais. III. Programa de educação e saúde em verminose. Revista de Saude Pública, 23: 189-195.

SCHALL, V. T.; JURBERG, P.; ALMEIDA, E. M.; CRAIG, C.; CAVALCANTE, F. \& BAGNO, S., 1987. Eরuucação em saúde para alunos de primeiro grau. Avaliação de material para ensino e profilaxia da esquistossomose. Revista de Salide Pública, 21: 387-404. 